\title{
Squamous metaplasia amplifies pathologic epithelial-mesenchymal interactions in COPD patients
}

\author{
Jun Araya, ${ }^{1}$ Stephanie Cambier, ${ }^{1}$ Jennifer A. Markovics, ${ }^{1}$ Paul Wolters, ${ }^{2}$ David Jablons, ${ }^{3}$ \\ Arthur Hill, ${ }^{3}$ Walter Finkbeiner, ${ }^{1}$ Kirk Jones, ${ }^{1}$ V. Courtney Broaddus, ${ }^{2}$ Dean Sheppard, ${ }^{2}$ \\ Andrea Barzcak, ${ }^{2}$ Yuanyuan Xiao, ${ }^{4}$ David J. Erle, ${ }^{2}$ and Stephen L. Nishimura ${ }^{1}$ \\ 1Department of Pathology, ${ }^{2}$ Department of Medicine and Lung Biology Center, Pulmonary Division, ${ }^{3}$ Department of Surgery, and \\ ${ }^{4}$ Department of Epidemiology and Biostatistics, Center for Bioinformatics and Molecular Biostatistics, UCSF, San Francisco, California, USA.
}

\begin{abstract}
Squamous metaplasia (SM) is common in smokers and is associated with airway obstruction in chronic obstructive pulmonary disease (COPD). A major mechanism of airway obstruction in COPD is thickening of the small airway walls. We asked whether SM actively contributes to airway wall thickening through alteration of epithelial-mesenchymal interactions in COPD. Using immunohistochemical staining, airway morphometry, and fibroblast culture of lung samples from COPD patients; genome-wide analysis of an in vitro model of SM; and in vitro modeling of human airway epithelial-mesenchymal interactions, we provide evidence that $S M$, through the increased secretion of IL-1 $\beta$, induces a fibrotic response in adjacent airway fibroblasts. We identify a pivotal role for integrin-mediated TGF- $\beta$ activation in amplifying SM and driving IL-1 $\beta$-dependent profibrotic mesenchymal responses. Finally, we show that SM correlates with increased severity of COPD and that fibroblast expression of the integrin $\alpha_{v} \beta_{8}$, which is the major mediator of airway fibroblast TGF- $\beta$ activation, correlated with disease severity and small airway wall thickening in COPD. Our findings have identified TGF- $\beta$ as a potential therapeutic target for COPD.
\end{abstract}

\section{Introduction}

Chronic obstructive pulmonary disease (COPD) is the fourth-leading cause of death worldwide and affects up to $50 \%$ of long-term smokers $(1,2)$. The major histopathologic correlates of airway obstruction in COPD are loss of alveolar walls and narrowing of the small airways (3). The relative contribution of each of these pathologic features to airway obstruction is not completely understood (4). However, recently, airway wall thickening has been identified as a major independent predictor of the severity of physiologic airway obstruction in COPD patients stratified by the criteria established by the Global Initiative for Obstructive Lung Disease (GOLD; http://www.goldcopd.com/), suggesting that airway-wall fibrosis contributes to airway obstruction (5). COPD is caused by the noxious effects of tobacco smoke, which leads to airway epithelial injury and the induction of changes such as squamous metaplasia (SM), the reversible replacement of the normal columnar epithelium by squamous epithelium (6). In 1978, Cosio et al. noted that SM correlated with the severity of airway obstruction, suggesting that SM and airway obstruction may be linked (7).

Changes in airway epithelium have the potential to alter the finely balanced reciprocal interactions between the epithelium and mesenchyme that influences cellular differentiation, the so-called epithelial-mesenchymal trophic unit $(8,9)$. Thus, SM developing in response to pathologic stimuli may alter normal homeostatic autocrine and paracrine interactions between the epithelium and

Nonstandard abbreviations used: BEGM, bronchial epithelial growth medium; Col I, type I collagen; COPD, chronic obstructive pulmonary disease; EDC, epidermal differentiation complex; GOLD, Global Initiative for Obstructive Lung Disease; IL-1RA, IL-1 receptor antagonist; LAP, latency-associated peptide; MT1-MMP, membrane type IMMP; P0, initial passage; P2, second passage; SM, squamous metaplasia.

Conflict of interest: The authors have declared that no conflict of interest exists. Citation for this article: J. Clin. Invest. 117:3551-3562 (2007). doi:10.1172/JCI32526. the surrounding fibroblast sheath. Recently, we provided evidence for a homeostatic role for integrin-mediated TGF- $\beta$ activation in a human model of the epithelial-mesenchymal trophic unit (10). In this model, fibroblastic integrin $\alpha_{v} \beta_{8}$-mediated TGF- $\beta$ activation was found to regulate the fibrogenic phenotype as well as synthesis and secretion of HGF, which influences the proliferation of adjacent airway epithelial cells (10).

TGF- $\beta$ is a major fibrogenic cytokine regulating both extracellular matrix deposition and immune homeostasis that may link SM and airway obstruction. TGF- $\beta$ is a major factor in driving SM of airway epithelial cells in vitro (11). Increased TGF- $\beta$ can be found in the small airway epithelium of COPD patients, and its levels correlate with the severity of obstruction $(12,13)$. Polymorphisms in the TGF- $\beta 1$ promoter have been shown to increase susceptibility to COPD (14). Adenoviral transfer of TGF- $\beta 1$ to murine lung has been shown to increase fibroblast accumulation around airways, and airway epithelial transgenic expression of TGF- $\beta$ causes peribronchiolar fibrosis, an effect that is reversible $(15,16)$. These results implicate TGF- $\beta$ mediated airway remodeling as a potential therapeutic target.

TGF- $\beta$ is ubiquitously expressed in 3 isoforms in all mammalian cell types and tissues but is found almost entirely in a latent form, consisting of the noncovalent interactions between the latencyassociated peptide (LAP) of TGF- $\beta$ and the mature peptide of TGF- $\beta$ and covalent interactions with latent TGF- $\beta$-binding proteins $(17,18)$. Thus, a major point of regulation of TGF- $\beta$ function is through its activation, which occurs by 2 general mechanisms, those that alter the conformation of LAP and those that result in the proteolytic cleavage of $\operatorname{LAP}(17,19-21)$. The integrins $\alpha_{v} \beta_{6}$ and $\alpha_{v} \beta_{8}$, heterodimers that have the $\alpha_{v}$ integrin subunit in common, can each bind to and activate latent TGF- $\beta(20,21)$ and together may account for the majority of TGF- $\beta 1$ activation during murine development (22). In the case of $\alpha_{v} \beta_{6}$, interaction with 
A

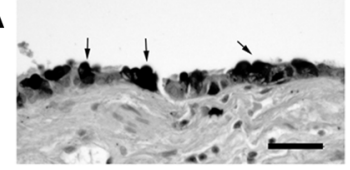

B
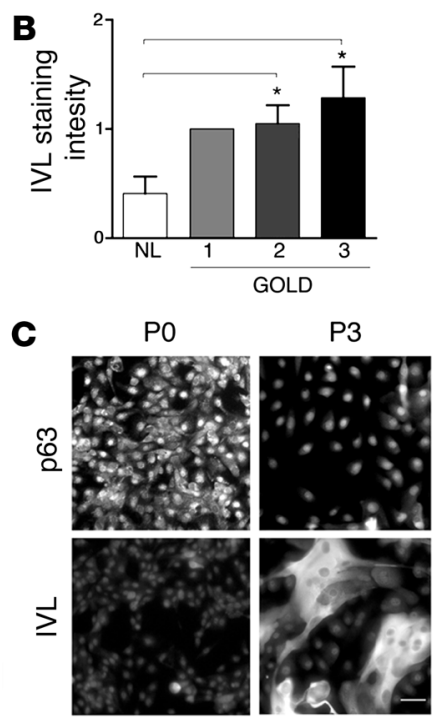

D

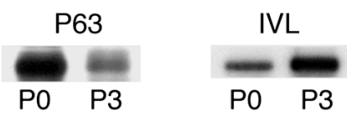

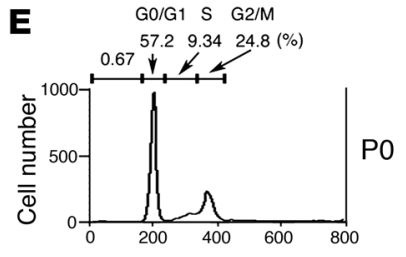

G0/G1 S G2/M $62.4 \quad 10.320 .4(\%)$
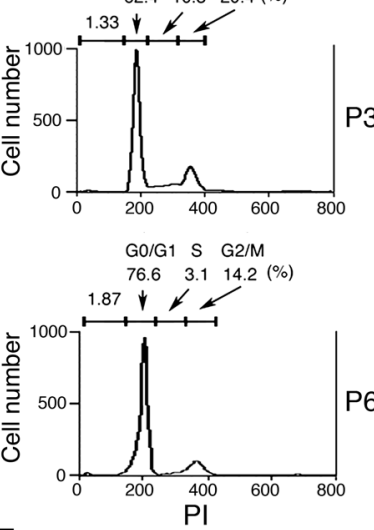

$\mathbf{F}$
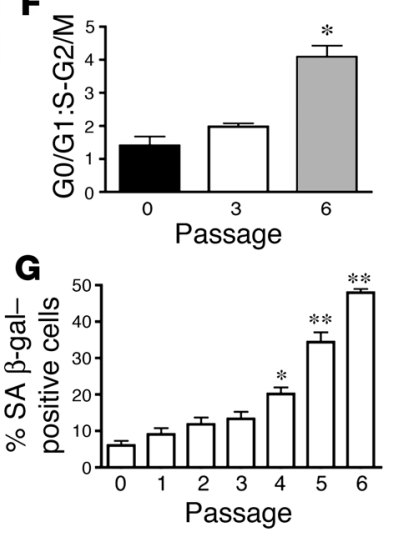

latent TGF- $\beta$ results in conformational alteration of LAP, allowing cell-associated active TGF- $\beta$ to interact with TGF- $\beta$ receptors on immediately adjacent cells (21). In the case of $\alpha_{v} \beta_{8}$, binding of latent TGF- $\beta$ results in the metalloproteolytic cleavage of LAP and release of active TGF- $\beta$ from the cell surface, where it can then act as an autocrine or paracrine factor (20). Both $\alpha_{v} \beta_{6}$ and $\alpha_{v} \beta_{8}$ are expressed by human airway epithelial cells; $\alpha_{v} \beta_{8}$ (but not $\alpha_{v} \beta_{6}$ ) is expressed by human airway fibroblasts.

Of the many cytokines that have been implicated in the pathogenesis of COPD, IL-1 $\beta$, a major proinflammatory cytokine, is of particular interest (23). IL-1 $\beta$ has been found in higher levels in alveolar macrophages from smokers and in cigarette smoke-treated airway epithelial cells from COPD patients (24). Transgenic overexpression of IL-1 $\beta$ in airway epithelial cells leads to airway inflammation, emphysema, and airway-wall thickening (25).

Here we report a link between SM of airway epithelium and airwaywall thickening through a mechanism involving increased secretion of IL- $1 \beta$ and increased integrin-mediated activation of TGF- $\beta$.

\section{Results}

SM in the small airways of COPD patients. Involucrin is a component of the cornified envelope of stratified squamous epithelium and is

\section{Figure 1}

SM correlates with increased GOLD stage of COPD in human lung samples, and SM can be induced during in vitro culture. (A) Involucrin (IVL), a marker of epidermal differentiation (26), stains small airway SM. Shown is a photomicrograph of metaplastic squamous cells (arrows) of a small airway from a COPD patient stained with anti-IVL. Scale bar: $50 \mu \mathrm{m}$. (B) IVL-staining intensity of lung samples from normal versus COPD patients stratified according to GOLD (www.goldcopd.com), and assessed by grading digital images ( $0-3$ scale) with 0 being absent; grade 1, 0-10\%; grade 2, $11-20 \%$; and grade $3,>20 \%$ cytoplasmic staining. ${ }^{*} P<0.05$. (C) Photomicrographs of P0 compared with P3 human bronchial epithelial cells. Upper panels are stained with the basal cell marker anti-p63 and lower panels with anti-IVL. Scale bar: $50 \mu \mathrm{m}$. (D) Western blotting of $40 \mu \mathrm{g}$ of P0 or P3 human bronchial epithelial cells total cell lysates for p63 and IVL. (E) Propidium iodide (PI) staining and flow cytometry of serially passaged human bronchial epithelial cells of a representative experiment $(n=3)$ showing the relative proportion of cells in the G0/G1, S, and G2/M phases of the cell cycle. (F) Relative proportion ( \pm SEM) of human bronchial epithelial cells $(n=3)$ in G0/G1 compared with S and G2/M phases of the cell cycle during serial passage. ${ }^{*} P<0.01$. (G) Senescence-associated $\beta$-gal (SA $\beta$-gal) staining of serially passaged human bronchial epithelial cells $(n=3)$. Shown is the percentage $( \pm$ SEM) of SA $\beta$-gal-positive cells. ${ }^{\star} P<0.01 ;{ }^{\star \star} P<0.001$.

a marker of SM in the airway epithelium (26). In the human small airways, involucrin staining was found in superficial metaplastic airway epithelial cells in areas of cuboidal airway epithelium devoid of cilia as well as in areas of morphologically obvious SM, confirming involucrin as a robust marker for SM (Figure 1A). Involucrin staining intensity in the small airway epithelium was significantly increased in patients with GOLD stages 2 and 3 COPD compared with normal controls (Figure 1B).

In vitro model of human airway epithelial squamous metaplasia. Human bronchial epithelial cells undergo SM during cell culture in the absence of retinoic acid (11). We found that in 2D cultures, in the low retinoic acid concentrations of our commercial airway epithelial medium preparation ( $0.3 \mathrm{nM}$; ref. 27), human bronchial epithelial cells phenotypically changed during serial passage from small poorly spread round cells to large and flattened squamouslike cells (Figure 1C). At the initial passage (P0), we determined that the cultures consisted mostly of basal cells, the progenitor cells of the human airway, because more than $95 \%$ of the cells expressed p63 (Figure 1C), a marker of basal cell differentiation (28). By the third passage (P3), the human bronchial epithelial cells displayed reduced p63 and strong involucrin staining (Figure 1C) typical of metaplastic squamous epithelial cells (29). Western blotting of human bronchial epithelial cell lysates confirmed the acquisition of a squamous cell phenotype during serial passage, since high p63 and low involucrin expression were found in $\mathrm{P} 0$ human bronchial epithelial cell lysates and low p63 and high involucrin expression were found in P3 human bronchial epithelial cell lysates (Figure 1D). These data are in agreement with previous studies using similar media, demonstrating that the primary cell in 2D tracheobronchial culture is initially the basal cell, which changes to an SM-like cell during serial passage (29).

SM in COPD patients is not only characterized by the onset of epidermal differentiation but is also a hyperproliferative state (30). Thus, we characterized cell proliferation and senescence of serially passaged human bronchial epithelial cells. The percentage of actively proliferating cells in the S and G2/M phases of the cell 


\section{Table 1}

Twenty-five most highly induced genes during human bronchial epithelial cells' serial passage

\begin{tabular}{|c|c|c|c|c|}
\hline & Gene & Description & Fold change & $B^{A}$ \\
\hline 1 & $I L 1 B$ & IL-1 $\beta$ & 13.4 & 2.8 \\
\hline 2 & KRT6B & Keratin 6B & 12.0 & 2.0 \\
\hline 3 & $I L 1 A$ & $\mathrm{IL}-1 \alpha$ & 9.7 & 2.0 \\
\hline 4 & S100A8 & S100 calcium-binding protein A8 & 8.5 & 0.9 \\
\hline 5 & LYSMD1 & cDNA DKFZp564C0671 & 8.0 & 1.9 \\
\hline 6 & SERPINE1 & Plasminogen activator inhibitor type 1 & 6.9 & 2.4 \\
\hline 7 & FPGS & Folylpolyglutamate synthase & 6.6 & 2.5 \\
\hline 8 & RHCG & Rh type C glycoprotein & 6.5 & 1.3 \\
\hline 9 & $T G F B I$ & TGF, $\beta$-induced & 6.4 & 0.1 \\
\hline 10 & PTHLH & Parathyroid hormone-like hormone & 5.3 & 2.7 \\
\hline 11 & NDUFA4L2 & NADH:ubiquinone oxidoreductase & 5.0 & 1.5 \\
\hline 12 & $M A L$ & Mal, T cell differentiation protein & 4.9 & 2.1 \\
\hline 13 & GJA1 & Connexin 43 & 4.9 & 0.5 \\
\hline 14 & FLJ21511 & Hypothetical protein FLJ21511 & 4.5 & 1.4 \\
\hline 15 & GPX3 & Glutathione peroxidase 3 & 4.5 & 0.5 \\
\hline 16 & $C D A$ & Cytidine deaminase & 4.4 & 2.4 \\
\hline 17 & $A R E G$ & Amphiregulin & 4.4 & 1.6 \\
\hline 18 & $D S C 2$ & Desmocollin 2 & 4.3 & 2.2 \\
\hline 19 & NDRG1 & N-myc downstream regulated gene 1 & 4.3 & 1.1 \\
\hline 20 & $I V L$ & Involucrin & 4.1 & 2.6 \\
\hline 21 & KRT14 & Keratin 14 & 3.9 & 1.7 \\
\hline 22 & DESC1 & Transmembrane protease, serpine $11 \mathrm{E}$ & 3.9 & 1.7 \\
\hline 23 & $A P O E$ & apoE & 3.9 & 0.4 \\
\hline 24 & MRC2 & Endocytic receptor & 3.9 & 0.8 \\
\hline 25 & A2ML1 & a2-macroglobulin-like 1 & 3.8 & 1.3 \\
\hline
\end{tabular}

${ }_{A} B$ represents the log-odds ratio where a value of greater than 0 is considered significant.

6.9-fold), were the first, third, and sixth most highly induced genes, respectively (Table 1). Other genes known to be induced by TGF- $\beta$ in epithelial cells that were also differentially expressed at least 2 -fold in P3 airway epithelial cultures (see Table 1 and http:// www.ncbi.nlm.nih.gov/geo/, Geo accession number: GSE7557) included the integrin $\beta 6$ (ITGB6) (31), the $\mathrm{T}$ cell differentiation protein $(M A L)(32)$, the TGF- $\beta$ inducible gene (BIGH3) (33), and laminin A3 (LAMA3) (32), suggesting increased autocrine TGF- $\beta$ signaling during serial passage. In addition, a number of genes involved in epidermal differentiation (KRT6B, S100A8, GJ1A, IVL, DSC2, KRT14, DESC1, A2ML) were highly induced during serial passage; 3 of these (KRT6, IVL, and KRT14) have been reported to label actively proliferating suprabasal cells in the squamous mucosa or in SM (34-37) (Table 1).

Immunocytochemistry confirmed the suprabasal differentiation state of P3 human bronchial epithelial cells since $80 \%, 61 \%$, and $88 \%$ of cells expressed keratin 6 , keratin 14, and involucrin, respectively (Supplemental Figure 1). A high percentage (42\%) of the involucrin-stained $\mathrm{P} 3$ cells were actively proliferating, since they were in the $\mathrm{S}$ or $\mathrm{G} 2 / \mathrm{M}$ phase of the cell cycle (Supplemental Figure 2). Finally, $76 \%, 67 \%$, and $90 \%$ of IL- $1 \beta$-positive P3 human bronchial epithelial cells coexpressed keratin 6 , keratin 14, and involucrin, respectively (Supplemental Figure 1). These data demonstrate that P3 human bronchial epithelial cells represent actively proliferating IL-1 $\beta$-producing suprabasal squamous cells.

IL- $1 \alpha$ and IL- $1 \beta$ are functionally redundant and bind to the same IL-1 receptor and endogenous soluble recep-

cycle remained high $(\sim 30 \%)$ and did not significantly change during the P0 to P3 culture period, but by P6, proliferation had markedly decreased due to an accumulation of cells in the G0/G1 phase of the cell cycle (Figure 1, E and F). The fraction of senescent cells did not significantly change between P0 and P3 but increased significantly in subsequent passages (Figure $1 \mathrm{G}$ ). We conclude that at $\mathrm{P} 3$, human bronchial epithelial cells in $2 \mathrm{D}$ culture approximate the hyperproliferative state of SM in vivo and avoid the in vitro phenomenon of replicative senescence.

Global analysis of gene expression during SM reveals induction of the proinflammatory mediators $I L-1 \alpha$ and IL-1 $\beta$. We analyzed the changes in human bronchial epithelial cell gene expression occurring during the culture period from P0 to P3 using high-density oligonucleotide microarrays. In the transition from P0 to P3, there were 278 genes induced and 225 genes repressed (503 total) that reached statistical significance (http://www.ncbi.nlm.nih.gov/geo/, Geo accession number: GSE7557). Gene ontology analysis of the statistically significant induced genes revealed enrichment of a number of functional categories, including cell motility, cytoskeletal assembly, ectodermal development, IL-1 receptor binding, cell proliferation, and cell adhesion (Supplemental Table 1; supplemental material available online with this article; doi:10.1172/ JCI32526DS1). Statistically significant repressed genes included only the immune response group (Supplemental Table 2).

Of the 503 statistically significant differentially expressed genes, 93 and 62 were at least 2-fold induced or repressed, respectively. Most notably, IL-1 $\beta$ (13.4-fold), IL-1 $\alpha$ (9.7-fold), and the TGF- $\beta$ responsive gene, plasminogen-activator inhibitor (SERPINE1, tor antagonist (IL-1RA) but differ in that IL-1 $\beta$ is secreted whereas IL- $1 \alpha$ exists in both a membrane-bound and cleaved (secreted) form. Increased levels of IL- $1 \alpha$ and IL-1 $\beta$ in P3 human bronchial epithelial cells were confirmed by RT-PCR (Figure 2A), cytokine antibody array (Figure 2B), and ELISA (Figure 2C). The increase in IL-1 $\beta$ in the supernatant of P3 airway epithelial supernatants was approximately $30 \mathrm{pg} / \mathrm{ml}$. This level is in 4-fold greater excess than found in synovial fluid from patients with rheumatoid arthritis (38). Finally, to confirm the physiological relevance of our 2D system, we used air-liquid interface culture conditions. Thus, human bronchial epithelial cells were grown on top of filters and only the basal surface of the cells was allowed to remain in contact with the medium, which simulates the anatomic arrangement in the airway in vivo (39). Human bronchial epithelial cells (P0) grown in air-liquid interface conditions for 21 days using SM-promoting medium conditions adopted a squamous metaplastic phenotype and expressed involucrin in the basal and suprabasal cells (Figure $2 \mathrm{D}$ ) and expressed IL-1 $\beta$ (Figure 2E). Air-liquid interface cultures grown in airway-differentiating medium adopted a pseudostratified ciliated columnar phenotype and expressed neither involucrin nor IL-1 $\beta$ (Figure 2D and Figure 2E).

In vitro SM closely mimics metaplastic squamous epithelium in COPD in vivo. We characterized and confirmed the increased expression of IL-1 $\beta$ and the epidermal differentiation genes found using P0-P3 oligoarrays by immunohistochemical staining of tissue samples of human airway SM from COPD patients and compared the staining pattern with normal and wounded epidermis, squamous mucosa, and SM from a variety of mucosal sites. Antibodies to 
A

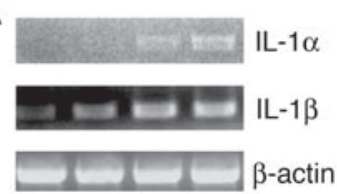

P0 P1 P2 P3

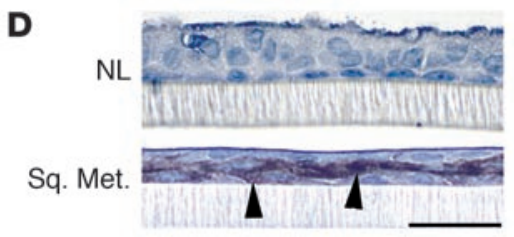

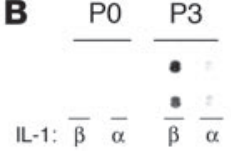

\section{C
है
음
ने
$=$}

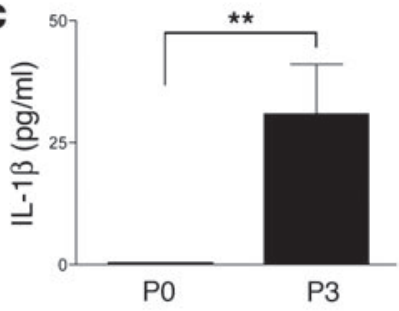

$\mathbf{E}$

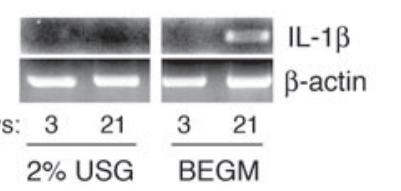

\section{Figure 2}

IL- $1 \alpha$ and IL-1 $\beta$ are induced during SM. (A) RT-PCR of total RNA from P0 to P3 human bronchial epithelial cells grown in $2 \mathrm{D}$ culture, using primers to IL-1 $\alpha$ and IL-1 $\beta$ and $\beta$-actin, as a control. Shown is a representative experiment from paired samples from 3 different patients with the same results. (B) Antibody cytokine array showing increased IL-1 $\beta$ and $-\alpha$ in conditioned medium taken from P0 or P3 human bronchial epithelial cells. Upper and lower panels are duplicates. Shown is a representative experiment from 3 separate patients showing similar results. (C) IL-1 $\beta$ ELISA assay showing increased IL-1 $\beta$ in conditioned medium from P0 compared with $\mathrm{P} 3$ human bronchial epithelial cells. ${ }^{* *} P<0.001$. (D) Involucrin immunostaining of P0 human bronchial epithelial cells grown in air-liquid interface culture for 21 days. Human bronchial epithelial cells grown in $2 \%$ Ultraser $\mathrm{G}$ (Invitrogen) produced differentiated pseudostratified ciliated columnar epithelium (NL, upper panel). When grown in BEGM (Clonetics), the cells adopted a squamous metaplastic phenotype and expressed involucrin (SM, lower panel). Arrows indicate involucrin staining of basal and suprabasal squamous metaplastic epithelial cells. Scale bar: $20 \mu \mathrm{m}$. (E) RT-PCR of total RNA harvested from human bronchial epithelial cells grown in air-liquid interface for 3 days or 21 days in differentiating medium (USG) or SM medium (BEGM) using primers to IL-1 $\beta$ or $\beta$-actin as controls.

IL-1 $\beta$ stained basal, suprabasal, and superficial cells of metaplastic squamous airway epithelium (Figure 3A) but did not stain normal airway epithelium from COPD patients (Figure 3B). The staining was specific, as no staining was observed after preabsorption of the antibody with the immunogen (Figure 3C). Antibodies to involucrin and keratin 6 stained the superficial and suprabasal cells of the squamous metaplastic epithelium (Figure 3, E and G) but not normal epithelium (Figure 3, F and H). Keratin 14 immunolocalized to the basal and suprabasal cells of SM (Figure 3I) and stained only the basal cells of the normal airway (Figure 3J). The basal and suprabasal cells of SM stained intensely with antibodies to integrin $\beta 6$ (Figure 3K) while the basal cells of the normal epithelium only lightly stained (Figure $3 \mathrm{~L}$ ); the opposite was true of integrin $\beta 8$ (Figure 3, M and N). The basal and suprabasal cells of SM stained intensely with antibodies to the proliferation marker Ki-67 (Figure $3 \mathrm{O}$ ) while fewer scattered basal cells of the normal airway stained (Figure 3P). The basal cell marker p63 (28) intensely stained basal cells and moderately labeled suprabasal cells of SM (Figure 3Q) while staining only basal cells of the normal airway (Figure 3R). A pattern of immunoreactivity similar to that seen in SM of the airways in COPD was seen in the squamous mucosa of the cervix, and in the epidermis at the edge of healing wounds (Supplemental Data and Supplemental Table 3). We conclude that P3 human bronchial epithelial cells in 2D culture closely approximate SM in the airway in COPD as well as in other mucosal sites.

IL-1 $1 \beta$ released by squamous metaplastic epithelium increases $\alpha_{v} \beta_{8}$ integrin expression and $\alpha_{v} \beta_{8}$-mediated TGF- $\beta$ activation in buman airway fibroblasts. We hypothesized that IL- $1 \beta$ released by metaplastic squamous epithelial cells contributed to a profibrotic fibroblast phenotype by increasing fibroblast TGF- $\beta$ activation, a largely integrin $\alpha_{v} \beta_{8^{-}}$ mediated process (10). Indeed, we found that $\alpha_{v} \beta_{8}$ integrin expression (Figure 4, A and B) and $\alpha, \beta_{8}$ integrin-mediated TGF- $\beta$ activation (Figure 4C) in human airway fibroblasts was increased by treatment either with recombinant IL-1 $\beta$ (data not shown) or by coculture with squamous metaplastic (P3) epithelial cells. Increased fibroblast $\beta 8$ expression caused by coculture with squamous metaplastic epithelial cells was IL-1 dependent, since IL-1RA, a physiological inhibitor of both IL-1 $\alpha$ and IL-1 $\beta$, almost completely inhibited the increase in $\beta 8$ expression (Figure 4D). The airway epithelial cells were the sole source of IL-1 in the coculture system because neither IL- $1 \alpha$ nor IL-1 $\beta$ mRNA could be detected in normal airway fibroblasts by RT-PCR (data not shown).

IL-1 1 released by squamous metaplastic epithelium causes an $\alpha_{v} \beta_{8^{-}}$and TGF- $\beta$-dependent switch to a fibrogenic fibroblast phenotype. Increased ECM production and increased fibroblast contractility are hallmarks of fibrotic responses seen in airway wall thickening, and increased type I collagen (Col I) and increased SMA ( $\alpha$ SMA) are key biochemical markers of that response. To assess the contribution of autocrine $\alpha_{v} \beta_{8}$-mediated TGF- $\beta$ activation to the profibrotic fibroblast phenotype, we used siRNA to knock down $\beta 8$ expression in airway fibroblasts. Treatment of normal airway fibroblasts with $\beta 8$ siRNA significantly reduced $\beta 8$ expression as assessed by RT-PCR (Figure 5A) and flow cytometry (Figure 5B) and completely inhibited $\alpha_{v} \beta_{8}$-mediated TGF- $\beta$ activation (Figure 5C). These effects were specific to $\beta 8$ siRNA since they were not seen with control siRNA (Figure 5, A-C). Neutralizing anti- $\beta 8$ and $\beta 8$ siRNA blocked only approximately $50 \%$ of the total TGF- $\beta$ activation as determined using a TGF- $\beta$ neutralizing antibody that inhibits the function of all 3 TGF- $\beta$ isoforms (Figure 5C). Thus, the incomplete inhibition of TGF- $\beta$ activation could be due to activation of TGF- $\beta 2$ by an $\alpha_{v} \beta_{8}$-independent mechanism, since $\alpha_{v} \beta_{8}$ is only involved in the activation of TGF- $\beta 1$ and $-\beta 3(10,20)$. Alternatively, the incomplete inhibition may be due to the relatively poor efficacy of the $\beta 8$-neutralizing antibody and the incomplete silencing achieved with $\beta 8$ siRNA (Figure $5 \mathrm{~A}$ ). Autocrine $\alpha_{v} \beta_{8}$-mediated activation of TGF- $\beta$ influenced the myofibroblast phenotype, since treatment of airway fibroblasts with $\beta 8$ siRNA reduced $\alpha$ SMA expression (Figure 5D) and Col I secretion (Figure 5E). Coculture of airway fibroblasts with P3 human bronchial epithelial cells led to an increase in Col I transcription and protein production by airway fibroblasts (Figure 5E). The increased production of collagen was IL- $1 \beta$ - and fibroblast $\beta 8$-dependent because the increase in Col I expression induced by coculture with P3 human bronchial epithelial cells could almost be completely inhibited by treatment of cocultures with IL-1RA (Figure 5E) or by transfection of airway fibroblasts with $\beta 8$ siRNA (Figure 5E).

IL-1 $\beta$-dependent increase in $\alpha_{v} \beta_{8}$-mediated activation of TGF- $\beta$ is MT1$M M P$ dependent. IL-1 $\beta$, while increasing $\beta 8$ expression, also has diverse functional effects, including increased transcription of mem- 


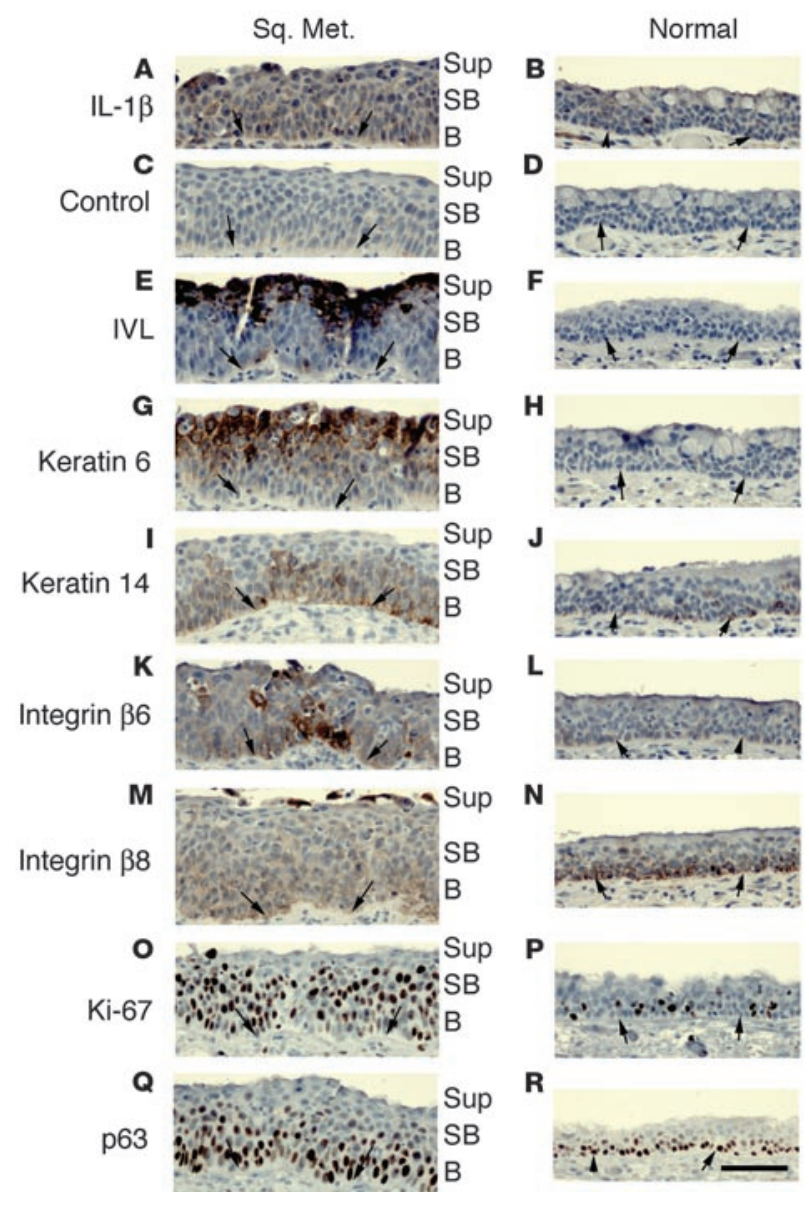

brane type I-MMP (MT1-MMP) (40) and TGF- $\beta$ (41), either of which could independently increase the efficiency of $\beta 8$ integrin-mediated TGF- $\beta$ activation (20). Indeed, treatment of airway fibroblasts with IL-1 $\beta$ also increased MT1-MMP activity (not shown). To determine whether the IL-1 $\beta$-dependent increase in fibroblast $\alpha_{v} \beta_{8}$-mediated TGF- $\beta$ activation was due to increased $\beta 8$ expression or to increased MT1-MMP activity, we overexpressed either $\beta 8$ or MT1-MMP in airway fibroblasts. Transient $\beta 8$ transfection significantly increased $\beta 8$ integrin expression and $\alpha_{v} \beta_{8}$-mediated TGF- $\beta$ activation (Figure 6 , $A$ and $B$ ) and did not affect MT1-MMP activity or expression (not shown). Conversely, overexpression of MT1-MMP, which increased MT1-MMP activity more than 100-fold (data not shown) had no effect on $\beta 8$ expression (data not shown) or $\alpha_{v} \beta_{8}$-mediated TGF- $\beta$ activation (Figure 6C). However, transfection of airway fibroblasts with MT1-MMP siRNA, which inhibited approximately $70 \%$ of MT1-MMP surface expression (Figure 6D) and activity (not shown), markedly inhibited $\alpha_{v} \beta_{8}$-mediated activation of TGF- $\beta$ (Figure 6E). In contrast, treatment of airway fibroblasts with IL- $1 \beta$ did not increase TGF- $\beta$ transcription (ratio of TGF- $\beta$ to $\beta$-actin transcript: nontreated, $0.97 \pm 0.11$; IL- $1 \beta$ treated, $0.87 \pm 0.16, n=3$ ) or secretion (TGF- $\beta$ activity as measured by TGF- $\beta$ bioassay: control, $1269 \pm 131$; IL-1 $\beta$ treated, $1152 \pm 129, n=4)$. These results demonstrate that the endogenous level of functionally active MT1-MMP present in airway fibroblasts is sufficient to support $\alpha_{v} \beta_{8}$-mediated activation of TGF- $\beta$ and that the IL- $1 \beta$-induced increases in TGF- $\beta$ activation are due to increased $\beta 8$ expression and not increased activity of MT1MMP or expression of TGF- $\beta$.

\section{Figure 3}

IL-1 $\beta$ is coexpressed with integrins $\alpha_{v} \beta_{6}$ and $\alpha_{v} \beta_{8}$ in hyperproliferative suprabasal squamous metaplastic airway epithelium of COPD patients. Immunostaining of adjacent paraffin sections from an airway with a focus of SM (Sq. Met.: A, C, E, G, I, K, M, O, and Q) compared with relatively normal airway mucosa $(\mathbf{B}, \mathbf{D}, \mathbf{F}, \mathbf{H}, \mathbf{J}, \mathbf{L}, \mathbf{N}, \mathbf{P}$, and $\mathbf{R})$ from a COPD patient using antibodies to (A and $\mathbf{B})$ IL-1 $\beta$; (C and $\mathbf{D})$ IL-1 $\beta$ preabsorbed with the immunogenic peptide (control); (E and F) the suprabasal markers anti-involucrin; ( $\mathbf{G}$ and $\mathbf{H})$ anti-keratin 6; ( $\mathbf{I}$ and $\mathbf{J}$ ) anti-keratin 14; ( $\mathbf{K}$ and $\mathbf{L}$ ) the TGF- $\beta$ activating integrins $\beta 6$; $(\mathbf{M}$ and $\mathbf{N}$ ) and $\beta 8$; ( $\mathbf{O}$ and $\mathbf{P})$ the cell proliferation marker Ki-67; ( $\mathbf{Q}$ and R) the basal cell marker p63. Arrows point to the basement membrane. Shown is a representative experiment of 3 showing similar results. Scale bar: $100 \mu \mathrm{m}$.

Increased TGF- $\beta$ activation during serial passage of airway epithelial cells. We next addressed the role of integrin-mediated activation of TGF- $\beta$ in driving SM. The TGF- $\beta$-activating integrin $\alpha_{v} \beta_{6}$ showed a dramatic increase in mRNA and surface expression during serial passage of airway epithelial cells. At P0, airway epithelial cells expressed little $\alpha_{v} \beta_{6}$. By P1, high levels of $\alpha_{v} \beta_{6}$ were detected, which persisted throughout later passages (Figure 7A). The other TGF- $\beta$-activating integrin expressed by airway epithelial cells, $\alpha_{v} \beta_{8}$, showed high expression in P0 cells and demonstrated a slight decrease during serial passage (Figure 7A). Approximately $50 \%$ of TGF- $\beta$ activation by airway epithelial cells from P0 to P3 was accounted for by the $\alpha_{v} \beta_{6}$ integrin, with the $\alpha_{v} \beta_{8}$ integrin contributing little to the total TGF- $\beta$ activation (Figure 7B). This is consistent with our previous observations that airway epithelial cells under these culture conditions require stimulation to support full $\alpha_{v} \beta_{8}$-mediated activation of TGF- $\beta$ (10). Anti- $\alpha_{v} \beta_{3}$ and anti- $\alpha_{v} \beta_{5}$ integrin antibodies showed no effects on TGF- $\beta$ activation (data not shown).

Airway epithelial $\beta 6$ expression has previously been reported to be increased by exogenous active TGF- $\beta$ (31). Here, increased $\beta 6$ expression was partially mediated by autocrine $\alpha_{v} \beta_{6}$-mediated activation of TGF- $\beta$, since treatment of airway epithelial cells (P2) with neutralizing anti- $\beta_{6}$ or TGF- $\beta$ antibodies caused a decrease in $\beta 6$ mRNA (Figure 7C). This effect was specific to $\alpha_{v} \beta_{6}$-mediated activation of TGF- $\beta$, since anti- $\beta 8$ had no effect (Figure $7 \mathrm{C})$. These results suggest that the integrin $\alpha_{v} \beta_{6}$ provides a self-amplifying autocrine loop of TGF- $\beta$ activation during the metaplastic process.

Role of autocrine and paracrine TGF- $\beta$ signaling in regulation of squamous differentiation of airway epithelial cells. We investigated the role of airway epithelial integrin $\alpha_{v} \beta_{6}$-mediated autocrine TGF- $\beta$ in promoting the expression of a panel of 6 genes that were differentially expressed during serial passage and that include members of gene clusters on chromosome 1q21 known as the epidermal differentiation complex (EDC) (Table 1 and http://www.ncbi.nlm.nih.gov/geo/, series accession GSE7557; IVL, DSC2, SPRR1A, SPRR1B, SPRR3, S100A7) (42, 43). Neutralizing anti- $\beta_{6}$ decreased the transcript expression of all 6 tested members of the EDC (Figure 7D). These results suggest that autocrine $\alpha_{v} \beta_{6}$-mediated activation of TGF- $\beta$ plays an active role in promoting squamous differentiation.

We next investigated the role of $\alpha_{v} \beta_{8}$-dependent paracrine secretion of active TGF- $\beta$ by airway fibroblasts in regulation of human bronchial epithelial cell $\beta 6$ expression. In P0 human bronchial epithelial cells, $\beta 6$ transcript expression was found to be TGF- $\beta$ dependent (Figure 8A). To determine the paracrine role of $\alpha_{v} \beta_{8^{-}}$ mediated activation of TGF- $\beta$ by airway fibroblasts in regulation 

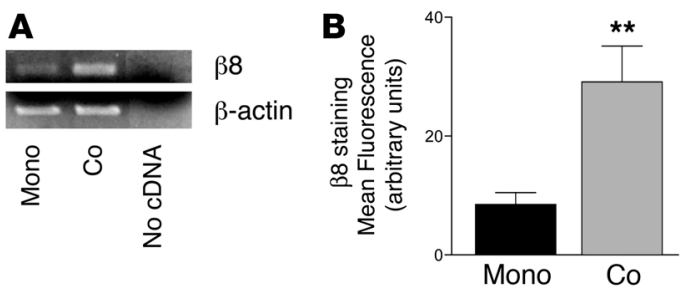
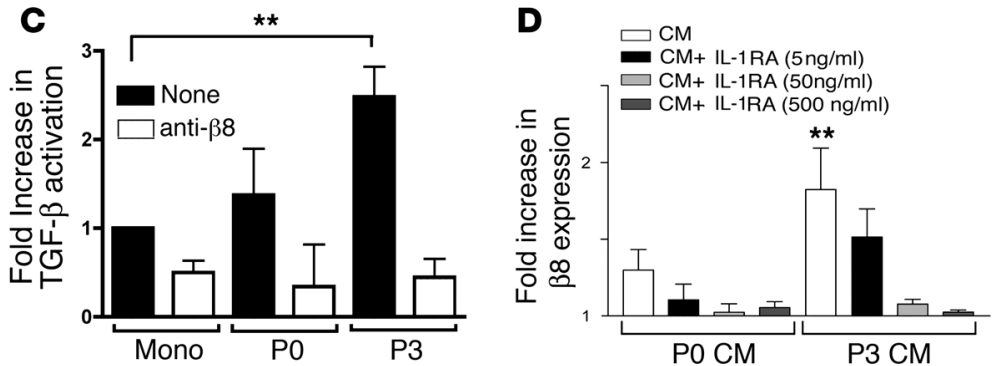

Figure 4

Paracrine secretion of IL- $1 \beta$ by P3 human bronchial epithelial cells increases $\beta 8$ expression and $\alpha_{v} \beta_{8}$-mediated TGF- $\beta$ activation of adjacent airway fibroblasts in a coculture model of the epithelial-mesenchymal trophic unit. Normal adult airway fibroblasts were cultured alone (Mono) or cocultured (Co) with P3 human bronchial epithelial cells grown on filter inserts. (A) Total fibroblast RNA was harvested and RT-PCR performed using primers specific for $\beta 8$ or $\beta$-actin, as a control. Shown is a representative experiment of 3 with similar results. No cDNA indicates a no template control. (B) Fibroblasts $(n=3)$ in mono- or coculture were stained with anti- $\beta 8$ and analyzed by flow cytometry. Shown is mean fluorescence in arbitrary units. (C) Monocultured fibroblasts or fibroblasts after 48-hour coculture with P0 or P3 human bronchial epithelial cells $(n=6)$ were cocultured with TGF- $\beta$ reporter cells in the presence of neutralizing anti- $\beta 8$, or no antibody (none). Shown is fold increase in TGF- $\beta$ activation relative to untreated fibroblasts in monoculture. (D) Airway fibroblasts $(n=3)$ were cocultured with P0 or P3 conditioned medium (CM) in the presence of no antagonist or different concentrations $(5,50$, or $500 \mathrm{ng} / \mathrm{ml})$ of IL-1RA, a naturally occurring soluble antagonist of IL-1 $\alpha$ and $\mathrm{IL}-1 \beta$. The fibroblasts were stained with anti- $\beta 8$ and analyzed using flow cytometry. Shown is the fold increase in $\beta 8$ expression compared with matched airway fibroblasts grown without conditioned medium. ${ }^{\star \star} P<0.001$.

of human bronchial epithelial cell $\beta 6$ expression, P0 human bronchial epithelial cells were cocultured with airway fibroblasts, which had been transfected with control or $\beta 8$ siRNA. The P0 human bronchial epithelial cell expression of the $\beta 6$ transcript was significantly increased by coculture with control transfected airway fibroblasts compared with P0 human bronchial epithelial cells cultured alone (Figure 8A). The majority of this increase was due to
TGF- $\beta$, since the increase could be largely blocked by neutralizing anti-TGF- $\beta$ (Figure 8A). Furthermore, the increase in expression of the human bronchial epithelial cells' $\beta 6$ transcript was partially dependent on $\alpha_{v} \beta_{8}$-mediated activation of TGF- $\beta$ by airway fibroblasts, since the majority of the increase in human bronchial epithelial cells' $\beta 6$ expression induced by coculture with airway fibroblasts could be blocked by transfection of fibroblasts with siRNA
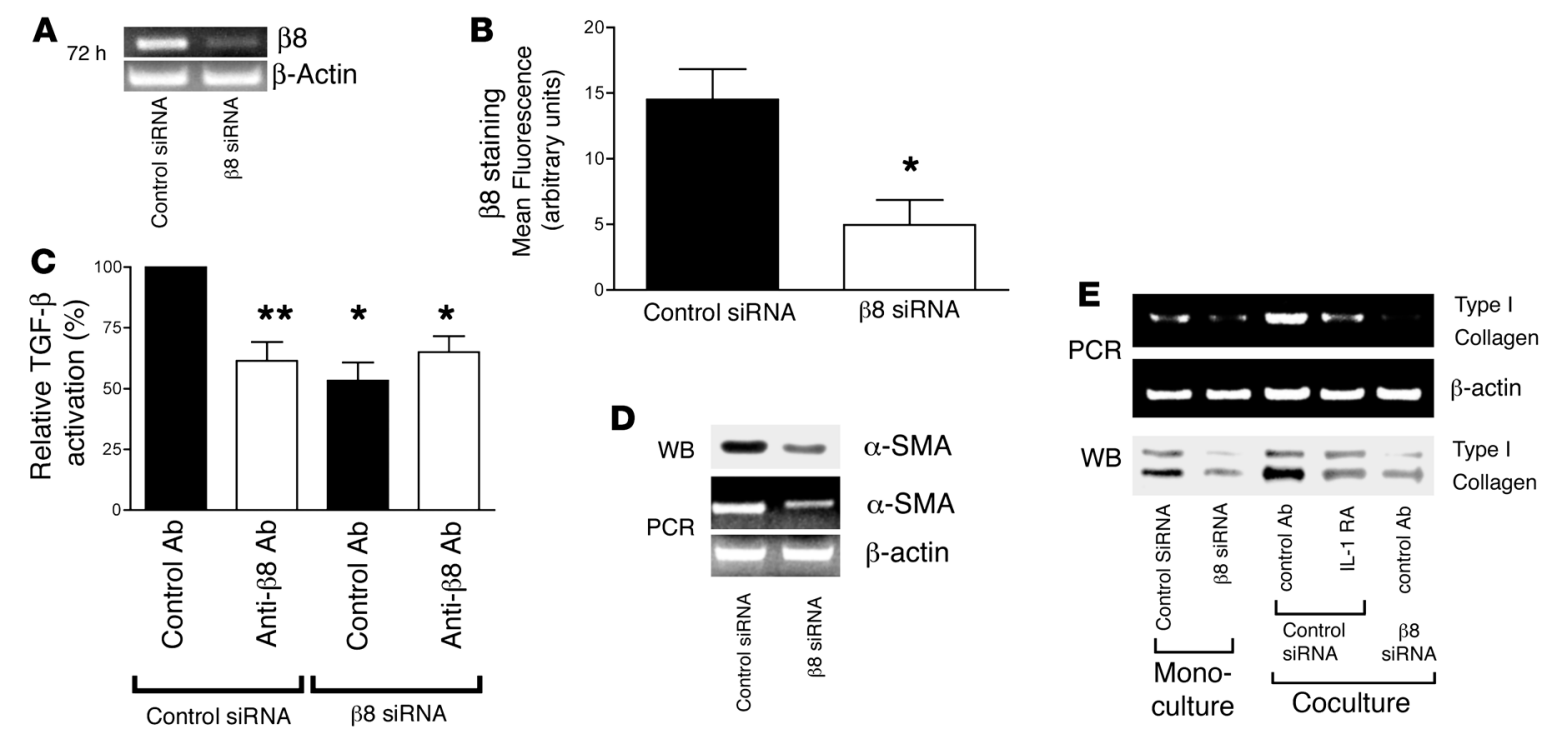

Figure 5

Autocrine $\alpha_{v} \beta$-mediated TGF- $\beta$ activation regulates the airway fibroblast contractile phenotype and collagen production. siRNA to $\beta 8$ or a control siRNA were transfected into normal adult airway fibroblasts and 72 hours following transfection were analyzed. (A) RT-PCR using primers to $\beta 8$ or $\beta$-actin as a control. Shown is a representative experiment of 4 showing similar results. (B) Flow cytometry using anti- $\beta 8$. Shown is mean fluorescence $(n=4)$ in arbitrary units \pm SEM. ${ }^{*} P<0.05$. (C) The TGF- $\beta$ reporter cell line, TMLC, in the presence of anti- $\beta 8$ or isotype-matched control antibodies $(n=3)$. TGF- $\beta$ activation is shown as relative to the total TGF- $\beta$ activation seen in control antibody, control siRNA-treated cells. ${ }^{*} P<0.05,{ }^{* *} P<0.001$. (D) Western blot (WB) using anti- $\alpha$ SMA or RT-PCR using primers to $\alpha$ SMA or $\beta$-actin as a control. Shown is a representative experiment of 3 showing similar results. (E) RT-PCR of fibroblasts cultured alone (monoculture) or in coculture treated with either a control antibody (control Ab) or IL-1RA using primers to Col I or $\beta$-actin as a control, or Western blot using anti-Col I. Shown is a representative experiment of 3 showing similar results. 

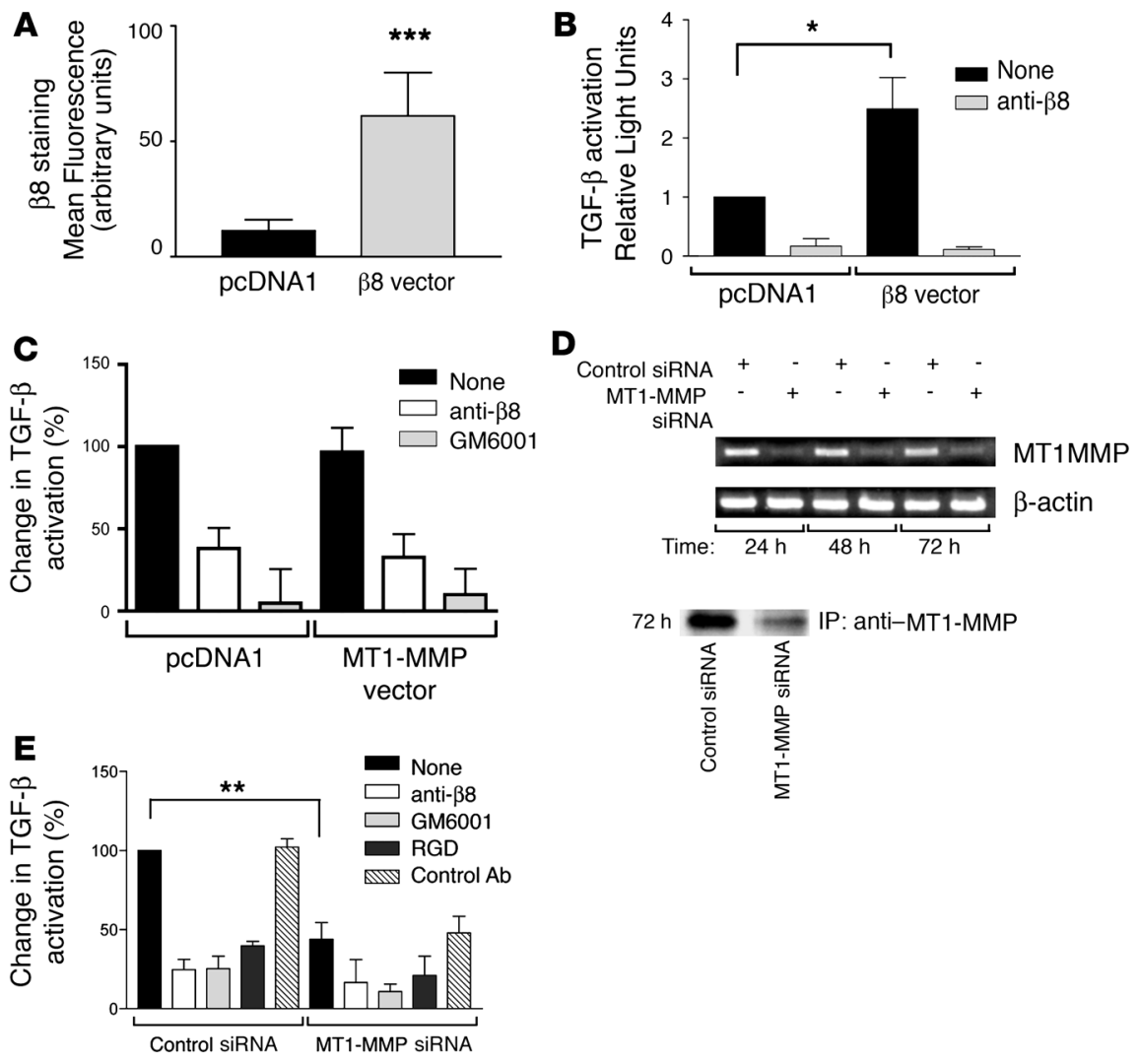

\section{Figure 6}

Increased $\alpha_{v} \beta_{8}$-mediated activation of TGF- $\beta$ in airway fibroblasts is mediated through increased $\beta 8$ expression and not increased MT1-MMP activity. (A) Airway fibroblasts $(n=4)$ were transiently transfected with a control vector (pcDNA1) or $\beta 8$ expression construct and assessed for $\beta 8$ expression by flow cytometry using anti- $\beta 8$. ${ }^{\star \star \star} P<0.001$. (B) Control or $\beta 8$ transfectants $(n=3)$ were cocultured with TGF- $\beta$ reporter cells in the presence or absence of neutralizing anti- $\beta 8$. Shown is TGF- $\beta$ activation relative to mock-transfected control. ${ }^{*} P<0.05$. (C) Airway fibroblasts transfected with a control or MT1-MMP expression vector were cocultured with TGF- $\beta$ reporter cells in the presence or absence of neutralizing anti- $\beta 8$ or the metalloprotease inhibitor GM6001. TGF- $\beta$ activation was determined using a pan-TGF- $\beta$ blocking antibody. (D) Airway fibroblasts were transfected with control siRNA or MT1-MMP siRNA and assessed for MT1-MMP expression by RT-PCR using primers to MT1-MMP or $\beta$-actin as a control at 24,48 , or 72 hours (upper panel). In the lower panel, transfected airway fibroblasts 72 hours after transfection were surface labeled. Cell lysates were immunoprecipitated with anti-MT1-MMP. Shown is a representative experiment of 3, showing similar results. (E) Airway fibroblasts $(n=3)$ transfected with control or MT1-MMP siRNA were cocultured with TGF- $\beta$ reporter cells in the presence or absence of anti-TGF- $\beta$, anti- $\beta 8$, a pan-metalloprotease inhibitor, GM6001, a TGF- $\beta 1$ RGD peptide (20), or isotype-matched control. The percentage of the total TGF- $\beta$ activation ( \pm SEM) was defined using an anti-TGF- $\beta$ neutralizing antibody. ${ }^{*} P<0.05 ;{ }^{* \star} P<0.001$.

to $\beta 8$ (Figure $8 \mathrm{~A}$ ). $\beta 6$ surface expression was also increased when P0 human bronchial epithelial cells were cocultured with control siRNA-treated airway fibroblasts (Figure 8B). This increase was significantly less when $\mathrm{PO}$ human bronchial epithelial cells were cocultured with $\beta 8$ siRNA-treated airway fibroblasts (Figure $8 \mathrm{~B}$ ).

Increased $\beta 8$ expression in small airway fibroblasts correlates with increasing severity of COPD and airway wall thickening. We used immunohistochemistry to evaluate the expression of $\beta 8$ in the fibroblasts surrounding the small airways in a cohort of normal and COPD patients. We found that the $\beta 8$ antibody strongly stained airway basal cells, as previously reported (44), as well as the subepithelial airway fibroblasts (Figure 9A). The intensity of $\beta 8$ staining correlated significantly with increasing severity of disease, as classified by GOLD (Figure 9B), and with increasing airway wall thickness (Figure 9C). We next evaluated lung fibroblasts harvested from normal and COPD patients for $\beta 8$ expression. Lung fibroblasts harvested from COPD patients expressed significantly more $\beta 8$ and activated more TGF- $\beta$ than fibroblasts from normal patients (Figure 9, D and E).

\section{Discussion}

Association of SM with COPD was described nearly 30 years ago (7). However, a mechanistic connection between SM and COPD may have been overlooked due to the long-held assumption that SM functions solely as a benign protective cellular reaction to injury. We have used recent advances in genome-wide analysis and gene silencing to parse out the complex role that SM plays in amplifying pathologic interactions between airway epithelium and fibroblasts in the evolution of airway remodeling in COPD. We have provided evidence of bidirectional paracrine signaling, mediated by the integrins $\alpha_{v} \beta_{6}$ and $\alpha_{v} \beta_{8}$, effecting both epithelial and mesenchymal differentiation in the adult airway (Figure 10). As such, amplification of integrin-mediated activation of TGF- $\beta$, by way of SM, may play a key role in derangement of morphoregulatory molecules and subsequent spatiotemporal interactions required to maintain homeostasis of the epithelialmesenchymal trophic unit.

The SM that we observe in P3 human bronchial epithelial cells shares many similarities with SM in COPD. Thus, expression of IL-1 $\beta$, basal, and suprabasal squamous epithelial markers, integrin subunits $\beta 6$ and $\beta 8$, and proliferation markers from our in vitro model mirror the immunohistochemical staining data of SM in human airways. These findings are consistent with the work of others suggesting that SM occurs through the increased recruitment of basal cells into an amplifying population of committed squamous lineage cells (29). This amplifying population occupies the suprabasal layer and expresses involucrin, keratin 6B, and keratin 14, which are known markers of actively proliferating suprabasal cells in normal squamous mucosa, SM either in the lung or other mucosal sites, and the epidermis at the edge of wounds (29, 30, 45-47).

During in vitro SM, the most highly induced gene, from an unbiased genome-wide analysis approach, was the proinflammatory gene IL-1 $\beta$. IL-1 $\beta$ has been shown to be expressed in the skin in vivo and in keratinocytes in $2 \mathrm{D}$ culture $(48,49)$, where it may represent epidermal "activation" in response to epithelial injury and 


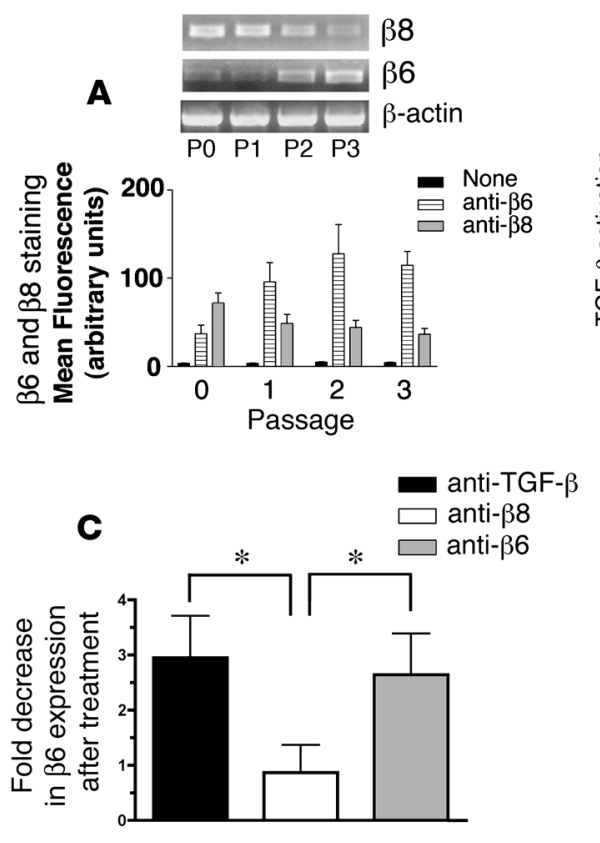

Figure 7

$\alpha_{v} \beta_{6}$-mediated TGF- $\beta$ activation forms a self-amplifying loop of increasing TGF- $\beta$ activation in human bronchial epithelial cells, which drives SM. Normal human bronchial epithelial cells in $2 \mathrm{D}$ culture $(n=3)$ were assessed during serial passage (P0-P3) for integrin $\alpha_{v} \beta_{6}$ and $\alpha_{v} \beta_{8}$ expression by (A, upper panel) RT-PCR using primers specific for $\beta 8, \beta 6$, or $\beta$-actin, as a control or (A, lower panel) flow cytometry using no antibody, anti- $\beta 6$, or anti- $\beta 8$ ( \pm SEM). (B) Human bronchial epithelial cells $(n=5)$ were tested for changes in integrin-mediated TGF- $\beta$ activation during serial passage using TGF- $\beta$ bioassay ( \pm SEM). TGF- $\beta$ activation was determined using pan-anti-TGF- $\beta$. (C) P2 human bronchial epithelial cells in 2D culture were treated for 4 days with no primary antibody, neutralizing anti-TGF- $\beta$, anti- $\beta 8$, or anti- $\beta 6$. RT-PCR was performed using primers to $\beta 8, \beta 6$, or $\beta$-actin, as a control $(n=5)$. Densitometry values were normalized to $\beta$-actin, and the results were expressed as fold decrease $( \pm S E)$ relative to control antibody-treated cells where a value of 1 represents no change from control antibody-treated cells. ${ }^{*} P<0.05$ (D) P2 human bronchial epithelial cells in 2D culture were treated with control antibody or neutralizing anti- $\beta 6$, and total RNA was harvested and assessed for the EDC genes $(42,43)$, involucrin (IVL), desmocollin-2 (DSC2), small proline rich protein-1A (SPRR1A), -1B (SPRR1B) $(n=3)$, -3 (SPRR3), or S100A7 $(n=2)$ using realtime PCR. Shown is the fold reduction (log 10) in expression of EDC genes after treatment with anti- 36 compared with control antibody-treated samples.

link innate immune responses to subsequent adaptive immune responses, ultimately promoting wound repair (50). Thus, the induction of IL- $1 \beta$ that occurs during SM of the airway epithelium may act as both an autocrine factor to influence gene expression to facilitate cell migration and wound closure and as a paracrine factor to recruit inflammatory cells and to induce matrix production and contractility of adjacent fibroblasts $(51,52)$. The basal, suprabasal, and superficial cells of SM in COPD all express increased IL-1 $\beta$, suggesting that both increased luminal and basal secretion of IL-1 $\beta$ are provided by the squamous metaplastic epithelium. This increased IL-1 $\beta$ secreted by SM may be an important additional source of IL- $1 \beta$, complementing the pool of IL- $1 \beta$ produced by immune effector cells.

We find that IL- $1 \beta$ secreted by metaplastic squamous airway epithelial cells promotes collagen expression by airway fibroblasts through increased fibroblast expression of $\alpha_{v} \beta_{8}$ and a subsequent increase in TGF- $\beta$ activation. In contrast, in a study utilizing a coculture model of keratinocytes and dermal fibroblasts, myofi- broblast differentiation was TGF- $\beta$ dependent but was antagonized by IL-1 $\beta$ (52). The discrepancy between these 2 studies likely represents inherent cell type-specific differences between airway and dermal fibroblasts. For instance, we have found that unlike human airway fibroblasts, human dermal fibroblasts do not express $\alpha_{v} \beta_{8}$ (53). However, it is likely that there are other differences between airway epithelial cells and keratinocytes in the cofactors that they secrete that can modify fibroblast responses to IL- $1 \beta$.

We, like others, have found that SM is an inevitable consequence of $2 \mathrm{D}$ but not airliquid interface culture, indicating that caution must be exercised when interpreting the results of many of the studies that have been published using human bronchial epithelial cells in 2D culture, as they may represent squamous metaplastic cells bearing little similarity to normal airway epithelium. On the other hand, 2D human bronchial epithelial cell culture provides an excellent model of the important in vivo phenomenon of SM.

We have created a simplified coculture model of the epithelial-mesenchymal trophic unit to study the reciprocal interactions between airway epithelial cells and the adjacent fibroblasts. In vivo, these cell types are separated by a basement membrane, where movement of proteins may be physically impaired by pore size or interactions with matrix components. Thus, our model, which does not provide an intact basement membrane, may overestimate the importance of paracrine secretion of IL- $1 \beta$ and TGF- $\beta$ in vivo. However, IL-1 $\beta$ and TGF- $\beta$ are compact proteins that appear to move freely through basement membranes $(54,55)$, which increases the likelihood that the paracrine interactions that we observe in our coculture model are physiologically relevant.

In the epithelial-mesenchymal trophic unit, we propose an important role for integrin-mediated TGF- $\beta$ activation in driving SM. However, blocking integrin-mediated TGF- $\beta$ activation only delays and does not completely prevent squamous differentiation in our systems. This is expected since integrin-mediated TGF- $\beta$ activation only accounts for approximately $50 \%$ of the total TGF- $\beta$ activation by airway epithelial cells. This partial effect could be due to antibody efficacy or other integrin-independent mechanisms of activating TGF- $\beta$, such as matrix metalloproteases- 2 and -9 (56), thrombospondin-1 (19), or plasmin (57). Finally, we have not defined the mechanism that initiates integrin-mediated TGF- $\beta$ activation by airway epithelial cells. We speculate that since normal airway epithelial cells express relatively high levels of $\alpha_{v} \beta_{8}$ and low levels of the $\alpha_{v} \beta_{6}$ integrin, some environmental stimulus may activate the pathways involved in airway epithelial $\alpha_{v} \beta_{8}$-mediated activation of TGF- $\beta$, thus increasing TGF- $\beta$ activation, which would increase $\beta 6$ expression and initiate SM. Our previous data support this hypothesis. For instance, we have found that P0 fetal tracheal epi- 
A

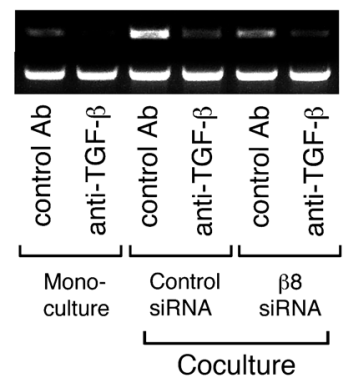

B

$\beta 6$-actin

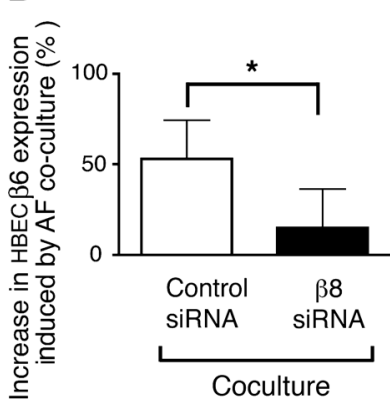

Figure 8

Fibroblast $\alpha_{v} \beta_{8}$-mediated activation of TGF- $\beta$ contributes to $\beta 6$ expression by adjacent human bronchial epithelial cells through a paracrine mechanism. (A) P0 human bronchial epithelial cells were cultured on filter inserts and were cultured alone (monoculture) or cocultured with control siRNA- or $\beta 8$ siRNA-transfected airway fibroblasts in the bottom chamber treated with control antibody (control $A b$ ) or neutralizing anti-TGF- $\beta$ for 48 hours. Total human bronchial epithelial cell RNA was harvested, and $\beta 6$ expression was determined by RT-PCR using primers to $\beta 6$ or $\beta$-actin, as a control. Shown is a representative experiment of 3 showing similar results. (B) P0 human bronchial epithelial cells grown on filter inserts were similarly cocultured alone or with control siRNA (white bar) or $\beta 8$ siRNA (black bar) transfected airway fibroblasts for 48 hours $(n=5)$. $\beta 6$ surface expression was determined by flow cytometry using anti- $\beta 6$. Shown is increase in surface expression relative to human bronchial epithelial cells in monoculture. Shown is SEM. ${ }^{*} P<0.05$.

thelial cells express $\alpha_{v} \beta_{8}$ but do not efficiently support $\alpha_{v} \beta_{8}$-mediated activation of TGF- $\beta$, which correlates with low expression of MT1-MMP (10). When fetal tracheal epithelial cells are stimulated with phorbol esters, MT1-MMP activity increases coincident with increasing $\alpha_{v} \beta_{8}$-mediated activation of TGF- $\beta$ (10). Therefore, we speculate that environmental stimuli, such as tobacco smoke, may also increase $\alpha_{v} \beta_{8}$-mediated activation of TGF- $\beta$ through a similar mechanism and thus initiate TGF- $\beta$-dependent SM.

\section{Figure 9}

Expression of the integrin $\beta 8$ is increased in small airway fibroblasts in COPD; its expression correlates with GOLD stage, airway wall thickness, and TGF- $\beta$ activation. Human lung samples obtained from patients with COPD $(n=22)$ or from normal controls $(n=12)$ were evaluated for $\beta 8$ expression by immunostaining $(\mathbf{A}-\mathbf{C})$, flow cytometry (D), and TGF- $\beta$ bioassay (E). In $\mathbf{A}$, a histologic section of a small airway with $\mathrm{SM}$ is depicted with strong $\beta 8$ staining in the basal cells (arrowheads) and moderate staining in the adjacent subepithelial fibroblasts (arrows). Scale bar: $50 \mu \mathrm{m}$. (B) Average $\beta 8$ staining intensity is shown for normal lung samples and samples from GOLD stage 1-3 patients based on the $0-3$ grading scale (see Methods). ${ }^{\star} P<0.05$, ${ }^{* *} P<0.01$. (C) Wall thickness was approximated by measuring the area of the airway wall from the basement membrane (BM) to the adventitia/length of the BM, using the method of Hogg (5). Shown is the relationship between wall thickness and $\beta 8$ staining intensity. (D and E) Fibroblasts were harvested from lung parenchyma from normal patients $(n=6)$ or patients with COPD $(n=5)$ and were (D) stained with anti- $\beta 8$ and analyzed using flow cytometry or (E) cocultured with TGF- $\beta$ reporter cells (TMLC) in the presence or absence of neutralizing anti- $\beta 8$. In $\mathbf{D}$, shown is mean fluorescence intensity \pm SE. ${ }^{*} P<0.05$. In E, TGF- $\beta$ activation is expressed as relative to the total light units obtained with anti-TGF- $\beta$. ${ }^{*} P<0.05$.

\section{Methods}

Cell culture, antibodies, and reagents. Adult airways were collected from first through fourth order bronchi from lobectomy specimens from resections performed for primary lung cancer or from normal lungs not used for transplantation. Informed consent was obtained from all surgical participants as part of an approved ongoing research protocol by the University of California San Francisco Committee on Human Research, in full accordance with the declaration of Helsinki principles. Normal human bronchial epithelial cells were isolated as previously described (58). Freshly isolated adult human bronchial epithelial cells were plated onto rat-tail Col I-coated $(10 \mu \mathrm{g} / \mathrm{ml})$ dishes and incubated overnight; then the medium was changed to bronchial epithelial growth medium (BEGM) (Clonetics). Human bronchial epithelial cells were serially passaged to P6. For air-liquid interface culture, P0 airway epithelial cells were seeded onto human placental collagen-coated filters (Sigma-Aldrich; Costar, Corning), as previously described using $2 \%$ Ultraser G-containing (Invitrogen) medium (58). Cells were cultured until confluent (as indicated by the ability to resist fluid movement through the epithelial layer), and then the medium on top of the filter was removed. To induce SM of air-liquid interface cultures, the medium was changed to BEGM (Clonetics), and the cultures were harvested at 3 and 21 days after exchange of the medium. Airway fibroblasts were cultured from the airway tissues remaining after epithelial cell isolation by the explant technique (58) and used P1 to P4. The TGF- $\beta$ reporter cell line, TMLC (gift of John Munger and Dan Rifkin, New York University, New York, New York, USA) were cultured as previously described (59).

Antibodies used were mouse anti- $\beta 8$ (clones $14 \mathrm{E} 5$ and $37 \mathrm{e} 1$; ref. 20 ), rabbit anti- $\beta 8$ (G17, Santa Cruz Biotechnology Inc.), anti- $\beta 3$ (clone LM609,

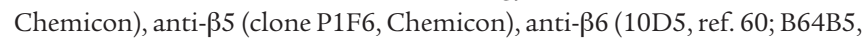
ref. 61), and mouse anti-involucrin, anti-keratin 6 , anti-keratin $14, \mathrm{p} 63$ (LabVision), rabbit anti-Ki-67 (Cell Marque Corp.), mouse anti-Col I (Southern Biotech), mouse anti- $\alpha$ SMA (Sigma-Aldrich), goat anti-IL-1 $\beta$
A

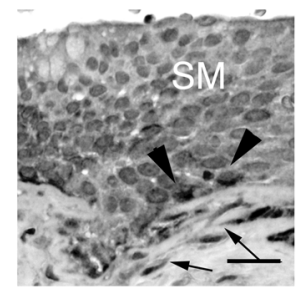

C

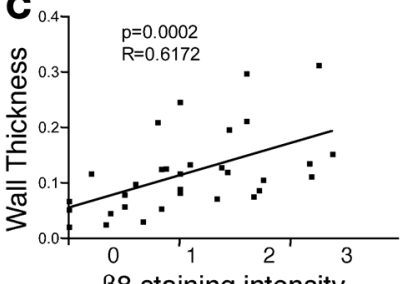

$\beta 8$ staining intensity

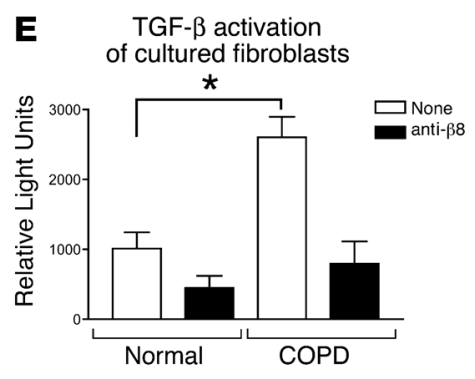

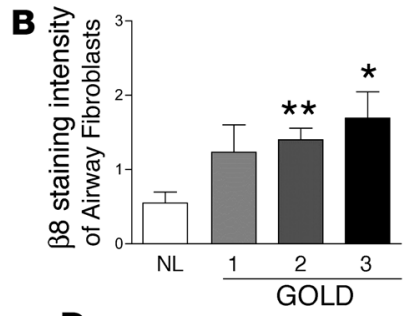

D

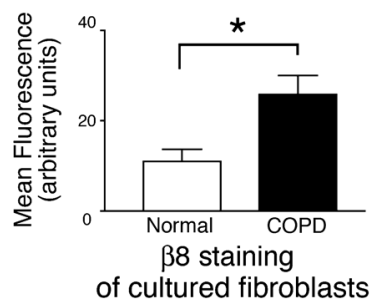




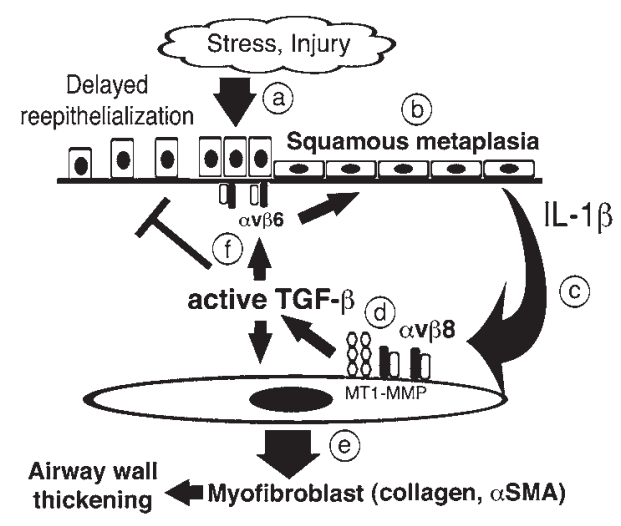

\section{Figure 10}

Hypothetical model of SM in the pathogenesis of airway wall thickening in COPD. (a) The normal airway epithelium when exposed to noxious stimuli responds by increasing TGF- $\beta$ production (12) and increasing TGF- $\beta$ activation, which increases expression of the $\beta 6$ integrin, a TGF- $\beta$ responsive gene (31) contributing to (b) a phenotypic switch to SM, a TGF- $\beta$ driven process (11). (c) Squamous metaplastic epithelial cells secrete increased IL-1 $\beta$, which acts a paracrine factor with adjacent airway fibroblasts. (d) Airway fibroblasts respond to IL- $1 \beta$ by increasing $\beta 8$ expression and $\alpha_{v} \beta_{8}$ mediated TGF- $\beta$ activation. Increased TGF- $\beta$ activation by airway fibroblasts causes (e) autocrine effects on the fibrogenic fibroblast phenotype by increasing Col I and $\alpha S M A$ and (f) paracrine effects on adjacent airway epithelium, which inhibits epithelial proliferation $(10,44,66)$ and contributes to the increased expression of $\beta 6$ by adjacent airway epithelial cells, forming a self-amplifying loop of TGF- $\beta$ activation. and blocking peptide (Santa Cruz Biotechnology Inc.), biotinylated affinity purified goat anti-IL-1 $\beta$ (R\&D Systems), anti-pan-TGF- $\beta$, and mouse anti-HLA class I (1D11 and W6/32, ATCC). Recombinant active TGF- $\beta 1$, IL-1 $\beta$ (R\&D Systems), IL-1RA (Affinity BioReagents), the pan-metalloprotease inhibitor GM6001 (Ryss Lab), and Vitrogen (Cohesion) were purchased. Rat-tail collagen was isolated as previously described (62).

Plasmids, siRNA, and transfection. The $\beta 8$, MT1-MMP, and control vectors were previously described $(20,63)$. The MT1-MMP, $\beta 8$, and negative control siRNAs were purchased (Ambion Inc.), and transfection of primary cultured cells were performed using the Amaxa Nucleofector (Amaxa Biosystems), using matched optimized transfection kits for airway epithelial cells and fibroblasts.

Immunocytochemistry, immunobistochemistry, and flow cytometry. Immunocytochemistry, immunohistochemistry, cell cycle analysis and flow cytometry were performed as previously described (44). Senescence-associated $\beta$-gal (SA $\beta$-gal), a marker of cellular senescence (64), was performed using human bronchial epithelial cells $\left(2 \times 10^{5}\right)$ grown on 12 -well culture plate according to the manufacturer's instructions ( $\beta$-galactosidase staining kit; BioVision Research Products).

Airway morphometry. Leftover human lung samples from pulmonary lobectomies or pneumonectomies performed at the San Francisco General Hospital or Moffit-Long Hospital, University of California San Francisco, for lung cancer, were gathered during the study period (from 2003 through 2006). Exclusion criteria included infection, prior radiation, or chemotherapy. Control lung tissues were obtained from donor lungs not utilized for lung transplantation, usually for reasons of size mismatching.

Microtome sections from 34 (22 COPD and 12 normal) lung samples were immunostained for involucrin or $\beta 8$. The slides were coded and blinded prior to pathologic assessment. Airway diameter was determined using a stage micrometer, and airways less than $2 \mathrm{~mm}$ in diameter were evaluated (mean $5.8 \pm 5.3$ airways/case). Each small airway was digitally imaged at 200× magnification (QCapture, v. 2.68.2). Digital images were assessed for $\beta 8$ immunostaining based on a $0-3$ scale, with 0 being absent staining; grade $1,0-10 \%$; grade $2,11-30 \%$; grade 3 , >30\% of airway cells or subepithelial fibroblasts with positive membrane and cytoplasmic staining. Involucrin immunostaining was also graded on a $0-3$ scale, with 0 being absent staining; grade $1,0-10 \%$; grade $2,11-20 \%$; grade $3,>20 \%$ cytoplasmic staining of superficial "squamoid" cells. Measurements of wall thickness were performed using the method of Hogg (5), which expresses wall thickness as a function of area of the airway wall/basement membrane length using image analysis software (ImageJ, v. 1.36b).

After immunohistochemical assessment, the clinical records from each patient were retrieved and the degree of pulmonary disability (stages 1 to 4 , with 4 being the worst) was determined using GOLD criteria. Preoperative pulmonary function tests (PFTs) were available for 18 of 20 patients undergoing surgery. The number of patients in each stage with PFTs available were as follows: stage $1, n=3$; stage $2, n=11$; stage $3, n=4$; and stage $4, n=0$.

$R N A$ isolation, polymerase chain reaction, and microarray analysis. RNA isolation and RT-PCR were performed as previously described (20). Real-time PCR was performed using the SYBR green method, as described (65). Primer sequences are available in supplemental data (Supplemental Table 4). Microarray methodology is available in supplemental data.

Immunoprecipitation analysis, Western blotting, zymography, and TGF- $\beta$ bioassay. Immunoprecipitations and SDS-PAGE were performed as previously described $(10,63)$. Western blotting of conditioned medium of coculture system was performed as described with minor modification (10). The TGF- $\beta$ bioassays and zymography to determine MT1-MMP activity were performed as previously described $(10,20)$.

Cytokine array and IL-1 $\beta$ ELISA. Airway epithelial cells $\left(3 \times 10^{6}\right)$ were cultured in $10-\mathrm{cm}$ collagen-coated tissue culture plates for 12-16 hours, washed 2 times with PBS, then incubated in serum-free DMEM for 72 hours. Cytokines in conditioned medium were detected with Cartesian Array Human Cytokine Set 1 from BioSource International (Invitrogen) following the manufacturer's instructions. IL- $1 \beta$ was measured in conditioned medium with an IL-1 $\beta$ Quantikine ELISA kit (R\&D Systems).

Coculture model of the epithelial-mesenchymal trophic unit. Airway epithelial cells $\left(2 \times 10^{5} /\right.$ well $)$ were seeded on vitrogen-coated $(10 \mu \mathrm{g} / \mathrm{ml}$ coating concentration) culture inserts ( $1 \mathrm{~mm}$ pore size; BD Biosciences) in a 24-well plate in BEGM (Clonetics) and cultured until confluent. Airway fibroblasts transfected with control or $\beta 8$ siRNA $(2.5 \mu \mathrm{g} /$ transfection) were cultured for $12-16$ hours on 24 -well $\left(2 \times 10^{5} /\right.$ well $)$ tissue-coated plate (BD Biosciences) in fibroblast growth medium. For the coculture experiments, the culture inserts containing the airway epithelial cells were placed into wells containing airway fibroblasts, and medium in both the upper and lower chambers were changed to DMEM without FCS in the presence or absence of control antibody, anti-TGF- $\beta$ antibody (1D11), anti- $\beta 6$ integrin antibody (10D5), anti- $\beta_{8}$ integrin antibody (37E1), or IL-1RA. After 48 or 72 hours coculture, integrin expression levels in airway epithelial cells were analyzed by FACS and RT-PCR. Col I gene expression in fibroblasts was evaluated by RT-PCR or by Western blotting of conditioned medium.

Statistics. Stepwise regression analysis with correction for clustering was used to compare $\beta 8$ staining intensity to airway wall thickness. Student's $t$ test was used for comparison of 2 data sets, analysis of variance for multiple data sets. Tukey's or Dunn's test were used for parametric and nonparametric data, respectively, to find where the difference lay. Significance was defined as $P<0.05$. Statistical software used was Prism v.3cx (GraphPad Software Inc.) and Stata v.9 (StataCorp LP). 


\section{Acknowledgments}

We would like to thank Charles McCullough (UCSF Division of Biostatistics) for biostatistical assistance and Rebecca Barbeau, Alicia Goodwin, and Alana Morris for technical assistance. This work was supported by NIH grants HL63993 and HL70622, the UCSF Academic Senate (to S. Nishimura), NIH grants HL72301 (to D. Erle), HL53949, HL083950, HL64353, AI024674 (to D. Sheppard), CA95671 (to V.C. Broaddus), and DK72517 and a grant from the Cystic Fibrosis Foundation (to W. Finkbeiner). We thank UCSF and Sandler Asthma Basic Research Center and Amha Atakilit for providing reagents.

Received for publication April 27, 2007, and accepted in revised form August 29, 2007.

Address correspondence to: Stephen L. Nishimura, San Francisco General Hospital, Building 3, Room 211, 1001 Potrero Avenue, San Francisco, California 94110, USA. Phone: (415) 206-5906; Fax: (415) 206-5988; E-mail: stephen.nishimura@ucsf.edu.
1. Vandevoorde, J., et al. 2007. Early detection of COPD: A case finding study in general practice. Respir. Med. 101:525-530.

2. International COPD Coalition. 2006. Global burden of COPD summit 2006. http://www.internationalcopd.org/materials/patients/learn/facts.aspx.

3. Hogg, J.C., Macklem, P.T., and Thurlbeck, W.M. 1968. Site and nature of airway obstruction in chronic obstructive lung disease. N. Engl. J. Med. 278:1355-1360.

4. Shapiro, S.D., and Ingenito, E.P. 2005. The pathogenesis of chronic obstructive pulmonary disease: advances in the past 100 years. Am. J. Respir. Cell Mol. Biol. 32:367-372.

5. Hogg, J.C., et al. 2004. The nature of small-airway obstruction in chronic obstructive pulmonary disease. N. Engl. J. Med. 350:2645-2653.

6. Puchelle, E., Zahm, J.M., Tournier, J.M., and Coraux, C. 2006. Airway epithelial repair, regeneration, and remodeling after injury in chronic obstructive pulmonary disease. Proc. Am. Thorac. Soc. 3:726-733.

7. Cosio, M., et al. 1978. The relations between structural changes in small airways and pulmonaryfunction tests. N. Engl. J. Med. 298:1277-1281.

8. Evans, M.J., Van Winkle, L.S., Fanucchi, M.V., and Plopper, C.G. 1999. The attenuated fibroblast sheath of the respiratory tract epithelialmesenchymal trophic unit. Am. J. Respir. Cell Mol. Biol. 21:655-657.

9. Shannon, J.M., Nielsen, L.D., Gebb, S.A., and Randell, S.H. 1998. Mesenchyme specifies epithelial differentiation in reciprocal recombinants of embryonic lung and trachea. Dev. Dyn. 212:482-494.

10. Araya, J., Cambier, S., Morris, A., Finkbeiner, W., and Nishimura, S.L. 2006. Integrin mediated TGF- $\beta$ activation regulates homeostasis of the pulmonary epithelial-mesenchymal trophic unit. Am. J. Pathol. 169:405-415.

11. Masui, T., et al. 1986. Type- $\beta$ transforming growth factor is the primary differentiation-inducing serum factor for normal human bronchial epithelial cells. Proc. Natl. Acad. Sci. U. S. A. 83:2438-2442.

12. de Boer, W.I., et al. 1998. Transforming growth factor- $\beta 1$ and recruitment of macrophages and mast cells in airways in chronic obstructive pulmonary disease. Am. J. Respir. Crit. Care Med. 158:1951-1957.

13. Takizawa, H., et al. 2001. Increased expression of transforming growth factor- $\beta 1$ in small airway epithelium from tobacco smokers and patients with chronic obstructive pulmonary disease (COPD). Am. J. Respir. Crit. Care Med. 163:1476-1483.

14. Celedon, J.C., et al. 2004. The transforming growth factor- $\beta 1$ (TGFB1) gene is associated with chronic obstructive pulmonary disease (COPD). Hum. Mol. Genet. 13:1649-1656.

15. Lee, C.G., et al. 2004. Early growth response gene 1-mediated apoptosis is essential for transforming growth factor beta1-induced pulmonary fibrosis. J. Exp. Med. 200:377-389.

16. Sime, P.J., Xing, Z., Graham, F.L., Csaky, K.G., and Gauldie, J. 1997. Adenovector-mediated gene transfer of active transforming growth factor- $\beta 1$ induces prolonged severe fibrosis in rat lung. J. Clin. Invest. 100:768-776.

17. Annes, J.P., Munger, J.S., and Rifkin, D.B. 2003.
Making sense of latent TGF- $\beta$ activation. J. Cell Sci. 116:217-224.

18. Rifkin, D.B. 2005. Latent transforming growth factor- $\beta$ (TGF- $\beta$ ) binding proteins: orchestrators of TGF- $\beta$ availability. J. Biol. Chem. 280:7409-7412.

19. Crawford, S.E., et al. 1998. Thrombospondin1 is a major activator of TGF- $\beta 1$ in vivo. Cell. 93: $1159-1170$.

20. Mu, D., et al. 2002. The integrin $\alpha v \beta 8$ mediates epithelial homeostasis through MT1-MMP-dependent activation of TGF- $\beta 1$. J. Cell Biol. 157:493-507.

21. Munger, J.S., et al. 1999 . The integrin $\alpha v \beta 6$ binds and activates latent TGF- $\beta 1$ : a mechanism for regulating pulmonary inflammation and fibrosis. Cell. 96:319-328.

22. Yang, Z., et al. 2007. Absence of integrin-mediated TGF $\beta 1$ activation in vivo recapitulates the phenotype of TGF $\beta 1$-null mice. J. Cell Biol. 176:787-793.

23. Barnes, P.J. 2004. Mediators of chronic obstructive pulmonary disease. Pharmacol. Rev. 56:515-548.

24. Rusznak, C., et al. 2000. Effect of cigarette smoke on the permeability and IL- $1 \beta$ and SICAM- 1 release from cultured human bronchial epithelial cells of never-smokers, smokers, and patients with chronic obstructive pulmonary disease. Am. J. Respir. Cell Mol. Biol. 23:530-536.

25. Lappalainen, U., Whitsett, J.A., Wert, S.E., Tichelaar, J.W., and Bry, K. 2005. Interleukin- $1 \beta$ causes pulmonary inflammation, emphysema, and airway remodeling in the adult murine lung. Am. J. Respir. Cell Mol. Biol. 32:311-318.

26. Tian, D., et al. 2006. Role of glycogen synthase kinase 3 in squamous differentiation induced by cigarette smoke in porcine tracheobronchial epithelial cells. Food Chem. Toxicol. 44:1590-1596.

27. Sachs, L.A., Finkbeiner, W.E., and Widdicombe, J.H. 2003. Effects of media on differentiation of cultured human tracheal epithelium. In Vitro Cell Dev. Biol. Anim. 39:56-62.

28. Wang, B.Y., et al. 2002. P63 in pulmonary epithelium, pulmonary squamous neoplasms, and other pulmonary tumors. Hum. Pathol. 33:921-926.

29. Jetten, A.M. 1989. Multistep process of squamous differentiation in tracheobronchial epithelial cells in vitro: analogy with epidermal differentiation. Environ. Health Perspect. 80:149-160.

30. Lee, J.J., et al. 2001. Long-term impact of smoking on lung epithelial proliferation in current and former smokers. J. Natl. Cancer. Inst. 93:1081-1088.

31. Wang, A., Yokosaki, Y., Ferrando, R., Balmes, J., and Sheppard, D. 1996. Differential regulation of airway epithelial integrins by growth factors. Am.J. Respir. Cell Mol. Biol. 15:664-672.

32. Zavadil, J., et al. 2001. Genetic programs of epithelial cell plasticity directed by transforming growth factor- $\beta$. Proc. Natl. Acad. Sci. U. S. A. 98:6686-6691.

33. Skonier, J., et al. 1992. cDNA cloning and sequence analysis of beta ig-h3, a novel gene induced in a human adenocarcinoma cell line after treatment with transforming growth factor-beta. DNA Cell Biol. 11:511-522.

34. Marenholz, I., et al. 2001. Identification of human epidermal differentiation complex (EDC)-encoded genes by subtractive hybridization of entire YACs to a gridded keratinocyte cDNA library. Genome
Res. 11:341-355.

35. Wiszniewski, L., Limat, A., Saurat, J.H., Meda, P., and Salomon, D. 2000. Differential expression of connexins during stratification of human keratinocytes. J. Invest. Dermatol. 115:278-285.

36. Sedghizadeh, P.P., et al. 2006. Expression of the serine protease DESC1 correlates directly with normal keratinocyte differentiation and inversely with head and neck squamous cell carcinoma progression. Head Neck. 28:432-440.

37. Galliano, M.F., et al. 2006. A novel protease inhibitor of the alpha2-macroglobulin family expressed in the human epidermis. J. Biol. Chem. 281:5780-5789.

38. Pay, S., et al. 2006. Synovial proinflammatory cytokines and their correlation with matrix metalloproteinase- 3 expression in Behcet's disease. Does interleukin-1beta play a major role in Behcet's synovitis? Rheumatol. Int. 26:608-613.

39. Gruenert, D.C., Finkbeiner, W.E., and Widdicombe, J.H. 1995. Culture and transformation of human airway epithelial cells. Am. J. Physiol. 268:L347-L360.

40. Ries, C., et al. 2007. MMP-2, MT1-MMP, and TIMP2 are essential for the invasive capacity of human mesenchymal stem cells: differential regulation by inflammatory cytokines. Blood. 109:4055-4063.

41. Lee, K.Y., et al. 2006. NF-kappaB and activator protein 1 response elements and the role of histone modifications in IL-1beta-induced TGF-beta1 gene transcription. J. Immunol. 176:603-615.

42. Chidgey, M., et al. 2001. Mice lacking desmocollin 1 show epidermal fragility accompanied by barrier defects and abnormal differentiation. J. Cell Biol. 155:821-832.

43. Mischke, D., Korge, B.P., Marenholz, I., Volz, A., and Ziegler, A. 1996. Genes encoding structural proteins of epidermal cornification and S100 calciumbinding proteins form a gene complex ("epidermal differentiation complex") on human chromosome 1q21. J. Invest. Dermatol. 106:989-992.

44. Cambier, S., et al. 2000. A role for the integrin $\alpha v \beta 8$ in the negative regulation of epithelial cell growth. Cancer Res. 60:7084-7093.

45. Serra, V., et al. 1989. Precocious appearance of markers of squamous differentiation in metaplastic cells of human endocervix. Arch. Gynecol. Obstet. 246:233-242.

46. Smedts, F., et al. 1993. Expression of keratins 1, 6, 15,16 , and 20 in normal cervical epithelium, squamous metaplasia, cervical intraepithelial neoplasia, and cervical carcinoma. Am. J. Pathol. 142:403-412.

47. Vaidyanathan, S., et al. 2003. Detection of early squamous metaplasia in bladder biopsies of spinal cord injury patients by immunostaining for cytokeratin 14. Spinal Cord. 41:432-434.

48. Groves, R.W., Mizutani, H., Kieffer, J.D., and Kupper, T.S. 1995. Inflammatory skin disease in transgenic mice that express high levels of interleukin $1 \alpha$ in basal epidermis. Proc. Natl. Acad. Sci. U. S. A. 92:11874-11878.

49. Maas-Szabowski, N., Shimotoyodome, A., and Fusenig, N.E. 1999. Keratinocyte growth regulation in fibroblast cocultures via a double paracrine mechanism. J. Cell Sci. 112:1843-1853.

50. Freedberg, I.M., Tomic-Canic, M., Komine, M., and 
Blumenberg, M. 2001. Keratins and the keratinocyte activation cycle. J. Invest. Dermatol. 116:633-640.

51. Eller, M.S., Yaar, M., Ostrom, K., Harkness, D.D. and Gilchrest, B.A. 1995. A role for interleukin-1 in epidermal differentiation: regulation by expression of functional versus decoy receptors. J. Cell Sci. 108:2741-2746.

52. Shephard, P., et al. 2004. Myofibroblast differentiation is induced in keratinocyte-fibroblast co-cultures and is antagonistically regulated by endogenous transforming growth factor-beta and interleukin-1. Am. J. Pathol. 164:2055-2066.

53. Cambier, S., et al. 2005. Integrin $\alpha v \beta 8$-mediated activation of transforming growth factor-beta by perivascular astrocytes: an angiogenic control switch. Am. J. Pathol. 166:1883-1894.

54. Bhowmick, N.A., et al. 2004. TGF-beta signaling in fibroblasts modulates the oncogenic potential of adjacent epithelia. Science. 303:848-851.

55. Dowd, C.J., Cooney, C.L., and Nugent, M.A. 1999. Heparan sulfate mediates bFGF transport through basement membrane by diffusion with rapid reversible binding. J. Biol. Chem. 274:5236-5244.
56. Yu, Q., and Stamenkovic, I. 2000. Cell surface-localized matrix metalloproteinase- 9 proteolytically activates TGF- $\beta$ and promotes tumor invasion and angiogenesis. Genes Dev. 14:163-176.

57. Sato, Y., and Rifkin, D.B. 1989. Inhibition of endothelial cell movement by pericytes and smooth muscle cells: activation of a latent transforming growth factor-beta 1-like molecule by plasmin during co-culture. J. Cell Biol. 109:309-315.

58. Finkbeiner, W.E. 1997. Respiratory cell culture. In The lung: scientific foundations. R.G. Crystal, editor. Lippincott-Raven Publishers. Philadelphia, Pennsylvania, USA. $415-433$

59. Abe, M., et al. 1994. An assay for transforming growth factor-beta using cells transfected with a plasminogen activator inhibitor-1 promoter-luciferase construct. Anal. Biochem. 216:276-284.

60 . Weinacker, A., et al. 1994. Role of the integrin $\alpha v \beta 6$ in cell attachment to fibronectin. Heterologous expression of intact and secreted forms of the receptor. J. Biol. Chem. 269:6940-6948.

61. Huang, X., Wu, J., Zhu, W., Pytela, R., and Sheppard, D. 1998. Expression of the human integrin beta 6 subunit in alveolar type II cells and bronchiolar epithelial cells reverses lung inflammation in beta 6 knockout mice. Am. J. Respir. Cell Mol. Biol. 19:636-642.

62. Montesano, R., Mouron, P., Amherdt, M., and Orci, L. 1983. Collagen matrix promotes reorganization of pancreatic endocrine cell monolayers into isletlike organoids. J. Cell Biol. 97:935-939.

63. Nishimura, S.L., Sheppard, D., and Pytela, R. 1994. Integrin $\alpha v \beta 8$. Interaction with vitronectin and functional divergence of the $\beta 8$ cytoplasmic domain. J. Biol. Chem. 269:28708-28715.

64. Dimri, G.P., et al. 1995. A biomarker that identifies senescent human cells in culture and in aging skin in vivo. Proc. Natl. Acad. Sci. U. S. A. 92:9363-9367.

65. Zhen, G., et al. 2007. IL-13 and epidermal growth factor receptor have critical but distinct roles in epithelial cell mucin production. Am J. Respir. Cell Mol. Biol. 36:244-253.

66. Fjellbirkeland, L., et al. 2003. Integrin $\alpha v \beta 8$-mediated activation of transforming growth factor-beta inhibits human airway epithelial proliferation in intact bronchial tissue. Am J Pathol 163:533-542. 